\title{
Anxiety and Cerebral Cortical Metabolism in Normal Persons
}

\author{
Bruno Giordani, Michael J. Boivin, Stanley Berent, Annette T. Betley, \\ Robert A. Koeppe. Jill M. Rothley, Jack G. Modell, Richard D. Hichwa, \\ and David E. Kuhl
}

Received September 27, 1989; revised version received February 13, 1990; accepted February 25, 1990.

\begin{abstract}
The State-Trait Anxiety Inventory (STAl) was administered to 43 normal volunteers immediately before and after a positron emission tomography (PET) procedure with [ $\left.{ }^{18} \mathrm{~F}\right]-2$-fluoro-2-deoxy-D-glucose $\left({ }^{18} \mathrm{~F}-\mathrm{FDG}\right)$. High traitanxious individuals had significantly higher state (situational) anxiety associated with the PET scan procedure than did low trait-anxious persons. State anxiety decreased significantly for all respondents following the PET scan procedure. No significant relationships between global or regional cortical metabolic rates and state anxiety were observed. The direct cortical metabolic effects of heightened anxiety in the scan setting, should they exist, are likely obscured in the normal variance of the ${ }^{18} \mathrm{~F}-\mathrm{FDG}$ method.
\end{abstract}

Key Words. Positron emission tomography, anxiety, cerebral metabolic rate, cortical lateralization, frontal lobe, State-Trait Anxiety Inventory.

Individuals often report increases in anxiety when undergoing medical diagnostic procedures, including positron emission tomography (PET), xenon-133 inhalation, and myelography (Dar et al., 1986; Gur et al., 1987). This has been attributed to concerns by the subjects that procedural aspects of the test might lead to physical discomfort, as well as apprehension about the diagnostic implications of the results (Reivich and Alavi, 1985; Berent et al., 1986). In evaluating the possible impact of anxiety on neuronal activity in the brain as measured by PET, Reivich and his colleagues studied 18 healthy males with the State-Trait Anxiety Inventory (STAI; Spielberger, 1983) during and after undergoing [ ${ }^{18 F]-2-f l u o r o-2-d e o x y-D-g l u c o s e ~}$ (18F-FDG) scans (see reviews by Reivich et al., 1983; Reivich and Alavi, 1985; Reivich and Gur, 1985). Their resulting scatterplots with state anxiety suggested a

Bruno Giordani, Ph.D., is Assistant Professor of Psychiatry and Psychology, University of Michigan, Ann Arbor, MI. Michael J. Boivin, Ph.D., is Adjunct Research Investigator, Department of Psychiatry, University of Michigan, and Associate Professor of Psychology, Spring Arbor College, Spring Arbor, MI. Stanley Berent, Ph.D., is Associate Professor of Psychiatry, Psychology, and Neurology; Annette T. Betley, B.S., is Nuclear Medical Technologist; Robert A. Koeppe, Ph.D., is Assistant Professor; Jill M. Rothley, B.S., is Senior Clinical Technologist, Division of Nuclear Medicine, Department of Internal Medicine; Jack G. Modell, M.D., is Assistant Professor of Psychiatry, University of Michigan. Richard D. Hichwa, Ph.D., is Associate Professor of Radiology, University of lowa, lowa City, IA. David E. Kuhl, M.D., is Chief, Division of Nuclear Medicine, and Professor of Internal Medicine and Radiology, University of Michigan. (Reprint requests to Dr. B. Giordani, Neuropsychology Program, Rm. 480, Med Inn Bldg., Box 0840, University of Michigan Medical Center, Ann Arbor, Ml 48 109-0840, USA.) 
curvilinear relationship with frontocortical metabolic rates. In another study with 14 normal subjects, cortical values for whole brain metabolism were negatively related to state anxiety scores (Gur et al., 1987). The authors suggested that this finding represented "the negative linear component of the postulated inverted-U relationship between anxiety and cortical activity" (p. 176). Other investigators, however, have obtained equivocal results when examining the relationship between cortical metabolic rates as measured with PET and anxiety level within the scan setting. Duara et al. (1984) obtained an anxiety score by ranking the incidence of verbal, motor, and behavioral signs of anxiety (e.g., fidgeting, excessive sweating, and hyperventilation) before and during PET scanning. They related this measure to a large number of regional metabolic values. Of the 150 coefficients examined, only three were significant (positive correlations) and this was interpreted as evidence of no overall relationship between cerebral metabolism and anxiety as measured by behavioral observation. Also, Buchsbaum et al. (1985) obtained no significant relationships between STAI scores and either local or global metabolic rates for schizophrenic patients.

To date, no conclusive relationship has been established between anxiety level within the PET scan setting and either global or regional measures of ${ }^{8} \mathrm{~F}-\mathrm{FDG}$ cerebral metabolism for normal subjects. The present study uses a standardized. objective procedure to clarify this relationship, as well as directly testing the hypothesis of a curvilinear relationship among these variables.

\section{Methods}

Subjects. Subjects were 43 normal volunteers who ranged in age from 18 to 71 years (mean $=$ $40.44, \mathrm{SD}=15.45$ ). Twenty of the subjects were males and 23 were females. All participants in the study underwent a thorough medical and neuropsychological evaluation before the exam and were found to be free of any medical, neurological, or $D S M-I I I-R$ (American Psychiatric Association, 1987) psychiatric disorder. Subjects were not taking any prescription drugs or over the counter medications for at least 3 days before the PET scan. Participants were recruited through local advertisements.

Anxiety Measure. The STAl is a unique self-report instrument in that it provides a quantifiable measure of both state and trait aspects of anxiety. State anxiety has been defined as the emotional reaction or pattern of responses occurring within an individual who appraises a situation as potentially dangerous or threatening (Spielberger, 1983). Trait anxiety measures the relatively stable degree to which one generally perceives certain situations as threatening, and responds with heightened state anxiety reactions (Spielberger, 1983). Thus, the trait measure pertains to "anxiety proneness."

Self-report measures of state anxiety with the STAI were first administered to subjects following completion of all consent forms and preliminary preparations, immediately before entering the scanner room to recline on the gantry. State and trait STAI measures of anxiety were also repeated immediately after the PET scan procedure was completed and subjects were removed from the scanner. In addition, all subjects were asked to take home the full state and trait STAI forms and complete them on the third evening following their scan. However, no attempt was made to follow up on this request and some of the subjects did not return their inventories.

The first 22 subjects were given the complete 20 -item STAI State scale. A standard five-item version of the STAI State scale (O'Neil, 1972) is also available and was used for the repeated monitoring of the remaining subjects. The modified STAI was specifically developed (O'Neil, 
1972) for use when time constraints might necessitate a shorter instrument than the entire 20 -item scale. This brief or modified STAI consists of the five items that had the highest item remainder correlation coefficients (items $1,3,5,13$, and 15) in the original validity studies for the development of the full inventory (see Spielberger et al, 1970, Appendix C). A high correlation $(r=0.92, d f=21, p<0.001)$ was obtained between the scores for the modified and full STAI for the first 22 subjects who took the full 20 -item scale. This demonstrated that the five-item version of the STAI State measure yielded essentially similar information as the full 20 -item scale. This modified scale could then be used for the remaining subjects to reduce the amount of time and paper work and facilitate the PET scanning procedure. In the results reported below, the analyses are presented for the full STAI State scale with the initial 22 volunteers as well as for the shortened five-item scale for all of the subjects. To evaluate any possible change in state anxiety resulting from the required arterial catheterization, a subset of patients $(n=20)$ was also given the modified State scale immediately after the insertion of the arterial catheter.

PET Scan Procedure and Regional Cortical Analysis. Subjects were scanned in a quiet, dimly lit room with minimal background noise, eyes blindfolded, ears unplugged, while resting, awake, and supine. Scans were begun $30 \mathrm{~min}$ after the i.v. injection of an ${ }^{18} \mathrm{~F}$-FDG bolus $(10 \mathrm{mCi})$. The ${ }^{18} \mathrm{~F}$-FDG was synthesized by a modification of the method of Ehrenkaufer and colleagues (Hamacher et al., 1986), with a radiochemical purity $>95 \%$. PET scans were performed with a Cyclotron Corporation PCT $4600 \mathrm{~A}$ tomograph having an inplane resolution of $11 \mathrm{~mm}$ full width at half maximum (FWHM) and a Z-axis resolution of 9.5 $\mathrm{mm}$ FWHM. A laser was used to align the head along the canthomeatal line with the head maintained in an immobile position throughout the study. Five planes with $11.5 \mathrm{~mm}$ centerto-center separation were imaged simultaneously. For each patient, four sets of scans were taken and included two interleaved sets through the lower brain levels and two interleaved sets through higher brain levels (total of 20 slices). Each slice was separated by $5.75 \mathrm{~mm}$, and an attenuation correction was calculated by a standard ellipse method modified to account for attenuation from the headholder and skull. Blood samples were collected from the radial artery.

Local cerebral metabolic rate for glucose $\left(1 \mathrm{CMR}_{\mathrm{glu}}\right)$ was calculated using a threecompartment model and single scan approximation described by Phelps et al. (1979) with gray matter kinetic constants derived from normal subjects (Hawkins et al., 1983) and a lumped constant of 0.51 . To obtain a global measure of ${ }^{18}$ F-FDG metabolism for the cerebral cortex, an automated region of interest program was used to define a symmetrical cortical ribbon adjacent to the outer rim of the brain and approximately $1.5 \mathrm{~cm}$ in width. Whole brain metabolic rate for glucose was then measured in the cortical ribbon for five consecutive slices, beginning with the lowest slice containing the basal ganglia. The average value for these five slices was used as the cortical metabolic rate $\left(\mathrm{ICMR}_{\mathrm{glu}}\right)$ for normalizing the various regional measures described below. For the purposes of regional. PET image analysis, three cortical slices were selected which would encompass the critical range of projections from the limbic region to the neocortex (cf. Nauta, 1972; Gray, 1982), and which had anatomical landmarks that allowed their reliable identification by three independent observers. The following three slices were selected for study: (A) the slice for which the frontal and occipital cortical regions were metabolically apparent, coincident with the head of the caudate nucleus; (B) the slice where the dorsal portions of the caudate nuclei were metabolically most prominent; and $(\mathrm{C})$ the initial slice (posterior to anterior) in which the lateral ventricles were fully bisected along the midline (see Fig. 1). The automated region of interest (AR) program was used to divide the cortical ribbon obtained for each of the three slices into four equal sections for each hemisphere, to obtain the average pixel value (absolute metabolic value given in $\mathrm{mg} / 100$ $\mathrm{g} / \mathrm{min}$ ) for each section (see Fig. 2). Cortical sections were then assigned to specific anatomical regions according to a comparison with the brain atlas developed by Matsui and Hirano (1978).

Since the variance between subjects has been shown to be considerably less for normalized regional metabolic values as opposed to absolute values (Duara et al., 1987), both absolute 


\section{Fig. 1. PET scan slices selected for analysis of ${ }^{18}$ F-FDG cortical metabolism}

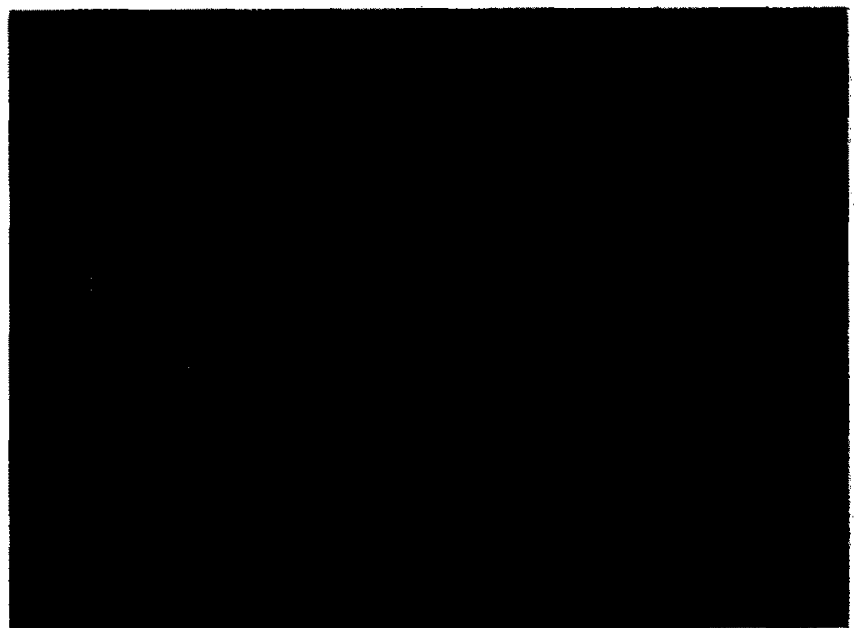

$\mathrm{PET}=$ positron emission tomography. ${ }^{18} \mathrm{~F}-\mathrm{FDG}-\left[{ }^{18} \mathrm{~F}-2-\right.$ fluoro-2-deoxy-D-glucose. The following 3 slices were selected for study: (A) the slice for which the frontal and occipital cortical regions were metabolically apparent, coincident with the head of the caudate nucleus; $(B)$ the slice where the dorsal portions of the caudate nuclei were metabolically most prominent; and $(C)$ the initial slice (posterior to anterior) in which the lateral ventricles were fully bisected along the midine.

\section{Fig. 2. Metabolic value for each of 8 sections}

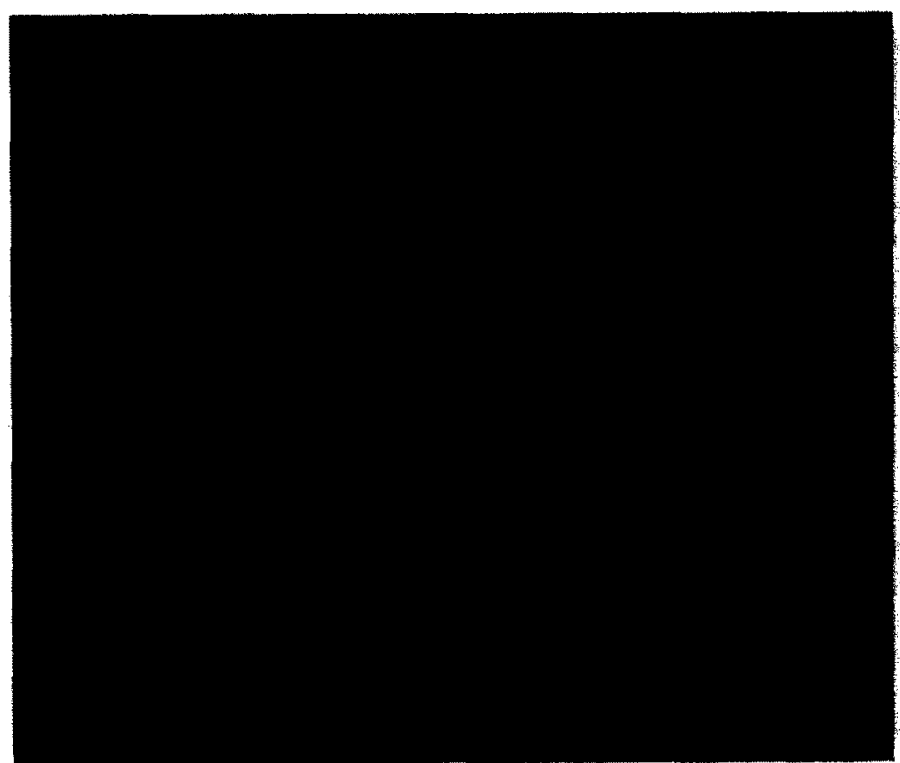

An automated region-of-interest program was used to divide the cortical ribbon for each of the 3 slices into 8 equal sections, 4 for each hemisphere, to obtain the metabolic value $(\mathrm{mg} / 100 \mathrm{~g} / \mathrm{min})$ for each section. 
and normalized values for the cortical sections were compared to the state anxiety measures. This is also consistent with other PET studies that have cxamined brain/bchavior relationships with regional cortical values (Haxby et al., 1986; Haier et al., 1988). The metabolic value for a given section ( $\left(\mathrm{CMR}_{\mathrm{glu}}\right)$ was normalized by dividing it by the metabolic value for the average $C M R_{\text {glu }}$ for the five slices described above. As a further means of evaluating any relationship between state anxiety and cortical metabolism, metabolic rates for the cortical ribbon sections were also normalized to a subcortical rather than a cortical value, the thalamus. Metabolic values for the thalamus were obtained from a regional analysis program described in Gilman et al. (1988).

Hemispheric differences were also examined as follows: the proportion of right to left hemispheric local cerebral metabolic activity was calculated for each slice by dividing the metabolic value for the sum of the right cerebral sections $\left(\mathrm{RBM}_{\mathrm{glu}}\right)$ by the sum of the metabolic values for the left $\left(\mathrm{LBM}_{\text {glu }}\right)$ plus right sections divided by two:

$$
\mathrm{RBM}_{\mathrm{glu}} /\left[\left(\mathrm{RBM}_{\mathrm{glu}}+\mathrm{LBM}_{\mathrm{glu}}\right) / 2\right] \text {. }
$$

Statistical Analyses. A three-factor analysis from the P3V program of the BMDP statistical software package (Jennrich and Sampson, 1985) was used to evaluate statistical significance of the present findings. This particular program computes a $X^{2}$ statistic for the maximum likelihood ratios when setting each of the factors of interest to zero. The dependent variable was the abbreviated STAI state anxiety score, and the independent variables were trait anxiety (above group median, below group median), gender (male, female), and the repeated measure of testing period (pre-scan, post-scan). Age was included as a covariate in this analysis. A paired $t$ test was used to compare the pre-scan and arterial-line anxiety scores to determine if patient anxiety changed significantly between these two points of the procedure. Similar comparisons were made for state and trait anxiety measures taken immediately after the scan procedure and at home a few days later.

Pearson product-moment correlation coefficients were used to study the relationship between the modified and full forms of the State scale and between anxiety levels and cerebral metabolic activity. As a specific test of the hypothesis of a curvilinear relationship between anxiety and metabolic values, polynomial regression coefficients were computed.

\section{Results}

Effects of Trait Anxiety Level and Gender on State Anxiety. For the repeated anxiety measures, there were no significant differences between state anxiety before the procedure (pre-scan) and following arterial catheter insertion $(t=-0.13, d f=18$, $p=0.90)$, or between post-scan and home scores for state $(t=0.71, d f=35$, $p=0.48)$ and trait $(t=1.98, d f=35, p=0.06)$ anxiety. To evaluate the significance of trait anxiety as a factor in the present results, the present sample was divided into two groups - those above and those below the median post-scan trait score (median score $=33$ ). When state anxiety was the dependent variable, the factor of trait anxiety level was significant $\left(x^{2}=10.32, d f=1, n=43, p<0.001\right)$. The abovemedian individuals had considerably higher overall state anxiety values (mean $=37.20, \mathrm{SD}=7.85)$ than did low trait-anxious individuals (mean $=26.96, \mathrm{SD}=$ 7.06) (see Fig. 3). However, neither group average could be considered unusually high or pathological according to the norms established for normal young adults for the STAI in Spielberger et al. (1970, Table 1).

The factor of gender also proved significant $\left(x^{2}=3.93, d f=1, n=43, p<0.05\right)$, with females having higher overall state anxiety (mean $=34.44, \mathrm{SD}=7.93$ ) than males $($ mean $=28.60, \mathrm{SD}=9.29$ ). There were, however, no significant gender 
Fig. 3. State anxiety at 3 time points in high and low trait-anxiety subjects

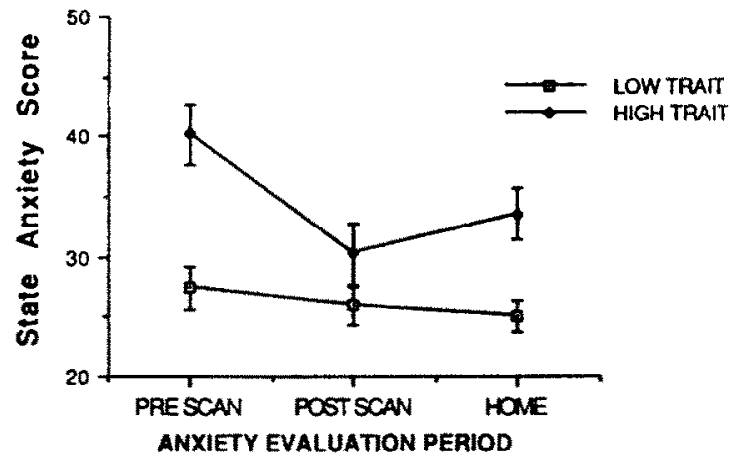

Subjects were grouped on the basis of trait anxiety (high vs. low) and compared on state anxiety (pre-scan, post-scan. and at home).

Table 1. State anxiety and Regional CMRglu: Pearson product-moment correlation coefficients for cortical regions with both modified and full STAI state anxiety measures

\begin{tabular}{|c|c|c|c|c|c|}
\hline \multirow[b]{2}{*}{ Cortical regions } & \multicolumn{2}{|c|}{ Before scan } & \multirow{2}{*}{$\begin{array}{c}\text { After } \\
\text { catheter } \\
\text { Modifled } \\
(n=19)\end{array}$} & \multicolumn{2}{|c|}{ After scan } \\
\hline & $\begin{array}{l}\text { Modified } \\
(n=43)\end{array}$ & $\begin{array}{c}\text { Full } \\
(n=22)\end{array}$ & & $\begin{array}{c}\text { Modified } \\
(n=41)\end{array}$ & $\begin{array}{c}\text { Full } \\
(n=22)\end{array}$ \\
\hline \multicolumn{6}{|l|}{ Left hemisphere' } \\
\hline \multicolumn{6}{|l|}{ Superior \& middle } \\
\hline Superior temporal & 0.03 & 0.18 & 0.01 & -0.14 & -0.05 \\
\hline $\begin{array}{l}\text { Middle \& inferior } \\
\text { temporal }\end{array}$ & -003 & & & & ח 29 \\
\hline Occipital & 0.15 & -0.04 & 0.13 & 0.02 & -0.08 \\
\hline \multicolumn{6}{|l|}{ Right hemisphere } \\
\hline \multicolumn{6}{|l|}{ Superior \& middle } \\
\hline Superior temporal & 0.06 & -0.06 & -0.19 & 0.15 & 0.09 \\
\hline \multicolumn{6}{|l|}{ Middle \& interior } \\
\hline temporal & -0.01 & -0.26 & -0.02 & 0.17 & 0.13 \\
\hline Occipital & 0.03 & -0.15 & 0.23 & 0.01 & 0.22 \\
\hline Whole cortex & 0.13 & 0.20 & -0.12 & 0.26 & 0.18 \\
\hline
\end{tabular}

Note. None of the coefficients in the above table are statistically significant. CMR ${ }_{\text {glu }}=$ cortical metabolic rate of glucose. STAI = State-Trait Anxiety Inventory.

1. The far left-hand column contains the cortical area that coincides with the slice $3.40 \mathrm{~cm}$ above the canthomeatal line for each of the cortical sections obtained with the automated region of interest program.

2. Also portions of the inferior frontal gyrus. 
differences for any of the 18 F-FDG measures used in the present analysis. For the sample as a whole, the repeated-measure factor was significant $\left(\chi^{2}=16.10, d f=1\right.$, $n=86, p<0.001)$ in that respondents generally had higher state anxiety before the scan $($ mean $=33.95, \mathrm{SD}=11.53)$ than afterwards (mean $=28.98, \mathrm{SD}=9.67)$. Furthermore, the interaction effect for trait anxiety level by repeated measure was significant $\left(x^{2}=10.81, d f=1, n=43, p<0.001\right)$, indicating that the decrease in state anxiety following the scan was greater for high trait-anxious individuals (see Fig. 3).

The gender by repeated-measure interaction was not significant $\left(\chi^{2}=0.13, d f=1\right.$, $n=86$ ). The proportion of females to males did not significantly differ between high and low average trait-anxious groups $\left(\chi^{2}=0.64, d f=1, n=43, p=0.42\right)$, though proportionately more females than males were high trait-anxious ( 12 females vs. 8 males) and fewer females were low trait-anxious (11 females vs. 12 males). The covariate, age, was not found to be significant in any of the above analyses. Furthermore, age was not significantly correlated to $\mathrm{CMR}_{\text {glu }}$ or any of the state or trait anxiety measures.

Relationship Between Cerebral Metabolism and State Anxiety. No significant correlations were found between $\mathrm{CMR}_{\text {glu }}$ and state anxiety before the scanning procedure, immediately after the insertion of the arterial catheter, or immediately after completion of the scanning procedure. This is apparent in a scatterplot of the relationship between $\mathrm{CMR}_{\text {glu }}$ and both the full and modified state anxiety measures (see Fig. 4). An anxiety value across the scanning session was also estimated by averaging the pre- and post-scan state anxiety scores. This value also did not correlate significantly with $\mathrm{CMR}_{\text {glu. }}$. Correlations between the above anxiety measures and the relative right-left ratio of hemispheric metabolic activity were also nonsignificant in every case. To test specifically for a curvilinear relationship between the various anxiety measures and $C M R_{\text {glu }}$, we replicated the above analyses with a polynomial regression model, and found that this did not significantly

Fig. 4. Relationship between cortical metabolic rate for glucose and state anxiety measures taken before the PET scan
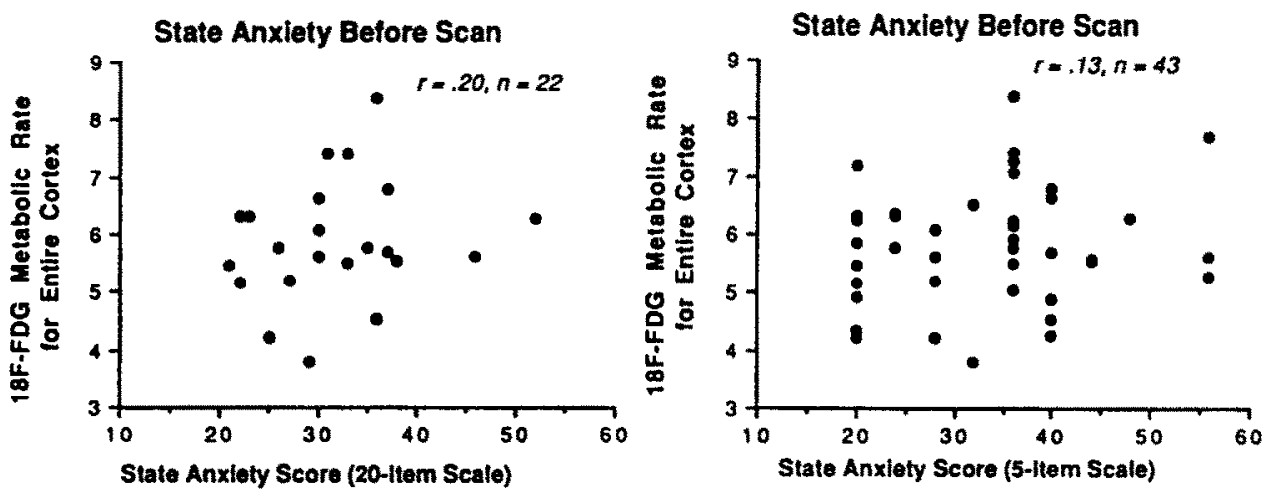

${ }^{18} \mathrm{~F}-\mathrm{FDG}=[$ [9F]-2-fluoro-2-deoxy-D-glucose. PET = positron emission tomography. Both the 5-item and 20-item forms of the Stait-Trait Anxiely Inventory were used. 
improve the regression fit, and in every case the correlations were insignificant. Using an analysis of variance model, when the present sample was divided into three groups on the basis of their pre-scan state anxiety scores, the three groups did not differ significantly from one another on $\mathrm{CMR}_{\text {glu. }}$. The same was true when the groups were divided on the basis of their post-scan state anxiety scores.

No significant correlations were found when comparing the state anxiety measures to the $\mathbf{I C M R}_{\text {glu }}$ values in the various cortical ribbon sections. Table I presents the coefficients between ICMR glu and the modified and full state anxiety measures immediately before the scan, after catheter insertion, and immediately after the PET scan session. This was true whether metabolic values were averaged across the three cortical slices or for each slice individually. Normalizing the metabolic rates to either $\mathrm{CMR}_{\text {glu }}$ or a subcortical structure (thalamus) did not result in statistically significant correlations. Testing for a hypothesized curvilinear relationship by replicating the above analyses using a polynomial regression model did not alter the nature of the results. Also, $z$ tests comparing the correlation coefficients from the frontal section to those sections corresponding to other cortical regions (temporal, parietal, and occipital lobes) did not reveal a differentially stronger relationship for the frontal region as compared to other regions of the brain.

\section{Discussion}

In the present study, high trait-anxious individuals had significantly higher state anxiety at the time of their PET scan than did low trait-anxious persons. Furthermore, the state anxiety of all subjects decreased significantly following completion of the PET scan procedure, particularly for those who were more trait anxious. That such factors as trait anxiety level and gender are significantly related to the propensity toward heightened state anxiety in the evaluative setting is consistent with findings in the general anxiety research literature (Green, 1976). The high correlation between modified and full state anxiety measures demonstrated that, for this study population, both versions of the scale were congruent. Also, the fact that no significant differences were found for state and trait scores between post-scan and home scores suggested that state anxiety had returned to approximate baseline by the completion of the scan and reaffirmed the stability of trait anxiety scores. The insertion of the arterial catheter as part of the PET procedure also did not appear to affect anxiety levels appreciably. Despite the fact that women have been reported to have significantly higher metabolic values under the ${ }^{18} \mathrm{~F}-\mathrm{FDG}$ Inethod (Baxter et al., 1987), we did not obtain this result with our gender groups, although women in our sample did report significantly higher state anxiety levels.

The significant differences in state anxiety between high and low trait-anxious subjects, as well as the significant reduction in state anxiety following the scan for both groups, suggests substantial individual differences in this behavioral response during even a "nonactivation state" scan session. In this study, however, neither regional nor global ${ }^{18} \mathrm{~F}$-FDG metabolism corresponded to these differences in selfreport anxiety measures. Lateralized differences were not observed with respect to cerebral hemispheric metabolic activity in relation to the anxiety measures. Thus, if anxiety level does indeed perturb the reliability of global or regional measures of 
cerebral metabolism, such effects are most likely lost in the normal variance of the fluorodeoxyglucose method.

The present results are consistent with previous reports (Duara et al., 1984; Buchsbaum et al., 1985) that found no significant correlations between anxiety and cerebral metabolism. A followup PET scan concomitant with low self-report of anxiety, however, would have served as a more powerful "test-retest" paradigm to demonstrate no differences in cerebral metabolic rate between high and low anxious conditions. Relevant to this issue is a study by Reiman et al. (1989) in which they reported significant blood flow increases in bilateral temporal poles for normal subjects anticipating painful electric shock. However, Rodriguez et al. (1989) reported statistically significant negative correlations between STAI state anxiety measures taken immediately following a xenon-133 scan and both regional and global cortical blood flow values. In interpreting these findings, though, it is important to consider the effects of anxiety-induced breathing changes on cerebral blood flow levels in the brain. Mountz et al. (1989), when taking into account hypocapnia (blood $\mathrm{PCO}_{2}$ measures) from anxiety-induced hyperventilation, found no significant differences in $\mathrm{CBF}$ between alternating resting and phobic arousal states. This was despite the fact that in their study, dramatic increases in state anxiety were demonstrated when the patients were presented with the anxiety-evoking stimulus.

There was a methodological difference between the present study and those previous reports that have noted a relationship between cerebral metabolism and state anxiety (Reivich et al., 1983; Reivich and Alavi, 1985; Reivich and Gur, 1985; Gur et al., 1987). Our subjects were scanned with ears open but eyes blindfolded, whereas in the other reports, subjects were scanned with both eyes and ears open. Mazziotta and Phelps (1985), however, noted significant regional hemispheric reductions in cortical metabolism in response to having both the eyes and ears occluded, suggesting that this methodological difference would not explain the disparity in our findings with those of Gur, Reivich, and colleagues.

Reivich and his co-workers noted that in their initial analyses, their findings suggested a curvilinear relationship between frontal cortical metabolism and anxiety. In a study of 14 subjects, Gur et al. (1987) also reported a curvilinear relationship between whole brain cortical metabolism and anxiety. Their suggestion of a curvilinear relationship was primarily derived from their use of the statistical analysis technique, local smoothing. They applied this technique to a sample of 14 subjects, even though O'Sullivan et al. (1986) have cautioned that this exploratory analysis approach is particularly suited only for samples over $n=50$. In the present study, we were unable to substantiate the proposed curvilinear relationships using standard polynomial regression techniques.

Gur et al. did note that their subjects undergoing PET scan tended to have higher state anxiety values than subjects undergoing xenon-133. The resulting negative metabolism/anxiety correlation was thought to reflect the negatively sloping portion of the postulated inverted- $U$ relationship between anxiety and cortical activity. The anxiety values for our subjects, however, constituted a very broad range (see Fig. 4) which should have encompassed both ends of the hypothesized inverted-U 
relationship. Individual difference characteristics such as age, tendency toward extreme levels of anxiety, or specific diagnostic groupings for medical disorders can be important considerations and deserve further study to clarify the relationship between anxiety and measures of cortical metabolism (Kuhl, 1983; Berent et al., 1986; Betley et al., 1988). Although we did not find a significant relationship between CMR glu and self-report anxiety measures, anxiety level may still be an important consideration in the study of brain-behavior relationships. For example, the impact of anxiety or behavioral disturbance on cognitive performance (Berent, 1986) may be especially important in interpreting the relationship between brain metabolism and cognition, especially during PET behavioral activation paradigms.

We conclude that subjects do react with increases in anxiety in response to the 18F-FDG procedure in a manner similar to reactions to other novel and potentially intimidating medical procedures. Individual differences are apparent in these findings and will need to be considered in future research and planning for routine patient care. While anxiety did not perturb CMR glu here, the effects could be different when groups other than normals are scanned or when radiotracers other than ${ }^{8}$ F-FDG are used

Acknowledgments. The preparation of this article was supported in part by National Institutes of Health Grant NS 15655. We gratefully acknowledge the assistance of the staff of the PET Center in the Division of Nuclear Medicine at the University of Michigan. Kenneth Guire and David Amato of the University of Michigan Department of Biostatistics served as the statistical consultants for this study and were very helpful in evaluating the analytical strategies used. Ms. Rohyn Byers provided very able assistance in the computer encoding of the data and her efforts are much appreciated. We also gratefully acknowledge the efforts of Ms. Patricia Bohland for her help in manuscript preparation.

\section{References}

Baxter, L., Jr.; Mazziotta, J.C.; Phelps, M.E.; Selin, C.E.; Guze, B.H.; and Fairbanks, L. Cerebral glucose metabolic rates in normal human females versus normal males. Psychiatry Research, 21:237-245, 1987.

Berent, S. Psychopathology and other behavioral considerations for the clinical neuropsychologist. In: Filskov, S.B., and Boll, T.J., eds. Handbook of Clinical Neuropsychology. Vol. 2. New York: John Wiley \& Sons, 1986. pp. 279-304.

Berent, S.; Hichwa, R.; Giordani, B.; Windisch, W.; Buchtel, H.; and Sackellares, J.C. Patients ${ }^{2}$ self-report of anxiety before, during and after positron emission tomographic scanning: Individual differences and their consequences for " (Suppl.):251, 1986.

Betley, A.; Boivin, M.J.; Giordani, B.; Rothley, J.; Berent, S.; Lehtinen, S.; Koeppe, R.A.; and Hichwa, R.D. A quantifiable method for evaluation of self report of anxiety and its relationship to diagnostic category and glucose cerebral metabolism. Journal of Nuclear Medicine Technology, 16 (Suppl.):Ab4-Ab5, 1988.

Buchsbaum, M.S.; DeLisi, L.; Holcomb, H.H.; Hazlett, E.; and Kessler, R. Cerebral glucography in schizophrenia. In: Greitz. T.; Ingvar, D.H.; and Widen, L., eds. The Metabolism of the Human Brain Studied With Positron Emission Tomography. New York: Raven Press, 1985. pp. 471-484. 
Dar, R.; Shacham, S.; and Tomarken, A.J. Anxiety and pain as predictors of distress during a myelography procedure. Journal of Pain Symptom Management, 1:21-24, 1986.

Duara, R.; Grady, C.; Haxby, J.; Ingvar, D.; Sokoloff, L.; Margolin, R.A.; Manning, R.G.; Cutler, N.R.; and Rapoport, S.I. Human grain glucose utilization and cognitive function in relation to age. Annals of Neurology, 16:702-713, 1984.

Duara, R.; Gross-Glenn, K.; Barker, W.W.; Chang, J.Y.; Apicella, A.; Loewenstein, D.; and Boothe, T. Behavioral activation and the variability of cerebral glucose metabolic measurements. Journal of Cerehral Blond Flow and Metaholism, 7:266-271, 1987.

Gilman, S.; Markel, D.S.; Koeppe, R.A.; Junck, L.; Kluin, K.J.; Gebarski, S.S.; and Hichwa, R.D. Cerebellar and brain stem hypometabolism in olivopontocerebellar atrophy detected with positron emission tomography. Annals of Neurology, 23:223-230, 1988.

Gray, J.A. The neuropsychology of anxiety: An enquiry into the functions of the septohippocampal system. Behavioral and Brain Sciences, 3:469-534, 1982.

Green, R.G. Personality. St. Louis: Mosby, 1976. pp. 144-169.

Gur, R.C.; Gur, R.E.; Resnick, S.M.; Skolnick, B.E.; Alavi, A.; and Reivich, M. The effect of anxiety on cortical cerebral blood flow and metabolism. Journal of Cerebral Blood Flow and Metabolism, 7:173-177, 1987.

Haier, R.J.; Siegel, B.V.; Nuechterlein, K.H.; Hazlett, E.; Wu, J.C.; Paek, J.; Browning, H.L.; and Buchsbaum, M.S. Cortical glucose metabolic rate correlates of abstract reasoning and attention studied with positron emission tomography. Intelligence, 12:199-217, 1988.

Hamacher, K.; Coenen, H.H.; and Stocklin, G. Efficient stereospecific synthesis of NCA$2\left[{ }^{18} \mathrm{~F}\right]$-fluoro-2-deoxy-D-glucose using aminopolyether supported direct nucleophilic substitution. Journal of Nuclear Medicine, 27:235-238, 1986.

Hawkins, R.A.; Mazziotta, J.C.; Phelps, M.E.; Huang, S-C.; Kuhl, D.F.; Carson, R.E.; Metter, R.J.; and Riege, W.H. Cerebral glucose metabolism as a function of age in man: Influence of the rate constants in the fluorodeoxyglucose method. Journal of Cerebral Blood Flow and Metabolism, 3:250-253, 1983.

Haxby, J.V.; Grady, C.L.; Duara, R.; Robertson-Tchabo, E.; Koziarz, B.; Cutler, N.R.; and Rapoport, S.I. Relations among age, visual memory, and resting cerebral metabolism in 40 healthy men. Brain and Cognition, 5:412-427, 1986.

Jennrich, R., and Sampson, P. General mixed model analysis of variance. In: Dixon, W.J., chief ed. BMDP Statistical Software. Berkeley: University of California Press, 1985. pp. 413-425.

Kuhl, D.E. Mapping local cerebral glucose utilization in normal aging and in cerebrovascular, degenerative, and epileptic disorders. In: Heiss, W.D., and Phelps, M.E., eds. Positron Emission Tomography of the Brain. New York: Springer-Verlag, 1983. pp. 128-138.

Matsui, T., and Hirano, A. An Atlas of the Human Brain for Computerized Tomography. New York: Igaku-Shoin, 1978.

Mazziotta, J.C., and Phelps, M.E. Results and strategies in studies of human sensory stimulation and deprivation with positron emission tomography. In: Greitz, T.; Ingvar, D.H.; and Widen, L., eds. The Metabolism of the Human Brain Studied With Positron Emission Tomography. New York: Raven Press, 1985. pp. 315-334.

Mountz, J.M.; Modell, J.G.; Wilson, M.; Curtis, G.C.; Lee, M.A.; Schmaltz, S.; and Kuhl, D.E. Positron emission tomographic evaluation of cerebral blood flow during state anxiety in simple phobia. Archives of General Psychiatry, 46:501-504, 1989.

Nauta, W. Connections of the frontal lobe with the limbic system. In: Laitinen, L.V., and Livingston, K.E., eds. Surgical Approaches in Psychiatry. Baltimore, MD: University Park Press, 1972. pp. 303-314.

O'Neil, H.F. Effects of stress on state anxiety and performance in computer-assisted learning. Journal of Educational Psychology, 63:473-481, 1972. 
O'Sullivan, F.; Yandell, B.S.; and Raynor, W.J. Automatic smoothing of regression functions in generalized linear models. Journal of the American Statistical Association, 81:96$103,1986$.

Phelps, M.E.; Huang, S-C.; Hoffman, E.J.; Selin, C.S.; Sokoloff, L.; and Kuhl, D.E. Tomographic measurement of local cerebral glucose metabolic rate in humans with (F-18) 2-fluoro-2-deoxyglucose: Validation of method. Annals of Neurology, 6:371-388, 1979.

Reiman, E.M.; Fusselman, M.J.; Fox,P.T.; and Raichle, M.E. Neuroanatomical correlates of anticipatory anxiety. Science. 243:1071-1074, 1989.

Reivich, M., and Alavi, A. Effect of psychophysiological stimuli on local cerebral glucose consumption in humans. In: Greitz, T.; Ingvar, D.H.; and Widen, L., eds. The Metabolism of the Human Brain Studied With Positron Emission Tomography. New York: Raven Press, 1985. pp. 305-313.

Reivich, M., and Gur, R. Cerebral metabolic effects of sensory and cognitive stimuli in normal subjects. In: Reivich, M., and Alavi, A., eds. Positron Emission Tomography. New York: Alan R. Liss, Inc., 1985. pp. 329-344.

Reivich, M.; Gur, R.C.; and Alavi, A. Positron emission tomographic studies of sensory stimuli, cognitive processes and anxiety. Human Neurobiology. 2:25-33, 1983.

Rodriguez, G.; Cogorno, A.; Gris, S.; Marenco, C.; Mesiti, F.; Nobili, F.; and Rosadini, G. Regional cerebral blood flow and anxiety: A correlation study in neurologically normal patients. Journal of Cerebral Blood Flow and Metabolism, 9:410-416, 1989.

Spielberger, C.D. Manual for the State-Trait Anxiety Inventory. Palo Alto, CA: Consulting Psychologists Press, 1983.

Spielberger, C.D.; Gorsuch, R.L.; and Lushene, R.E. STAI Manual for the State-Trait Anxiety Inventorv. Palo Alto. CA: Consulting Psychologists Press, 1970. 